JOURNAL DE PHYSIQUE

Colloque $\mathrm{Cl}$, supplément au $\mathrm{n}^{\circ} 2$, Tome 47, février 1986

page $c 1-285$

\title{
MORPHOLOGICAL CHARACTERIZATION OF SIC MATERIALS
}

\author{
J.L. CHERMANT, M. COSTER and R. MOUSSA \\ Equipe Matériaux-Microstructure du L.A. 251, ISMRa, Université, \\ F-14032 Caen Cedex, France
}

\begin{abstract}
Résumé - L'analyse quantitative d'images a été utilisée pour mesurer les principales caractéristiques morphologiques de quelques nuances de SiC-Al : caractéristiques granulométriques, forme et anisotropie des cristaux. L'homogénéité de ces céramiques a été étudiée par des méthodes statistiques.

Abstract - Quantitative image analysis were used to measure the main morphological characteristics of some SiC-Al materials : size distribution characteristics, shape and anisotropy of the SiC-crystals. Statistical methods were utilized to inform on the homogeneity of these materials.
\end{abstract}

\section{I - INTRODUCTION}

For ceramic materials the role of the microstructure on the mechanical or electrical properties is very important. For example, the creep behaviour of SiC materials is governed by the amount of the intergranular phase, its distribution between the boundaries, and also by the mean grain size of the SiC crystals $/ 1,2,3 /$. In these conditions it is necessary to define the morphology of the microstructure of ceramic materials and quantitative image analysis is strongly advised $14 /$.

The aim of this paper is to show what types of parameters are determined using this technic in the case of silicon carbide materials. The first problem to solve is to obtain a correct image. This requires a perfect metallography.

\section{II - TECHNICAL PROCEDURES}

Four batches (from Elektroschmelzwerk, F.R.G.) of SiC with aluminium additive were used: $\mathrm{SiC}-\mathrm{AO} 3$ with 0.3 wt $\%$ of $\mathrm{Al}$ and $\mathrm{SiC}-\mathrm{Al} 5$ with $1.5 \mathrm{wt} \%$ of $\mathrm{Al}$. This last batch has been heat treated during two different times and noted SiC-A15 EI and E2, /1/. These materials have been polished using classical methods : diamond pastes of different mean grain sizes $(14,7,3$ and $1 \mu \mathrm{m})$ and then a chemical etching in a boiling Murakami solution $\left(24 \mathrm{~g} \mathrm{NaOH}+42 \mathrm{~g} \mathrm{FeK}_{3}(\mathrm{CN})_{6}\right.$ in $\left.100 \mathrm{~cm} \mathrm{H}_{2} \mathrm{O}\right)$, during $5 \mathrm{mn}$. Optical micrographs of SiC-Al 1.5 wt \% are shown on figure 1 for two mean grain sizes.
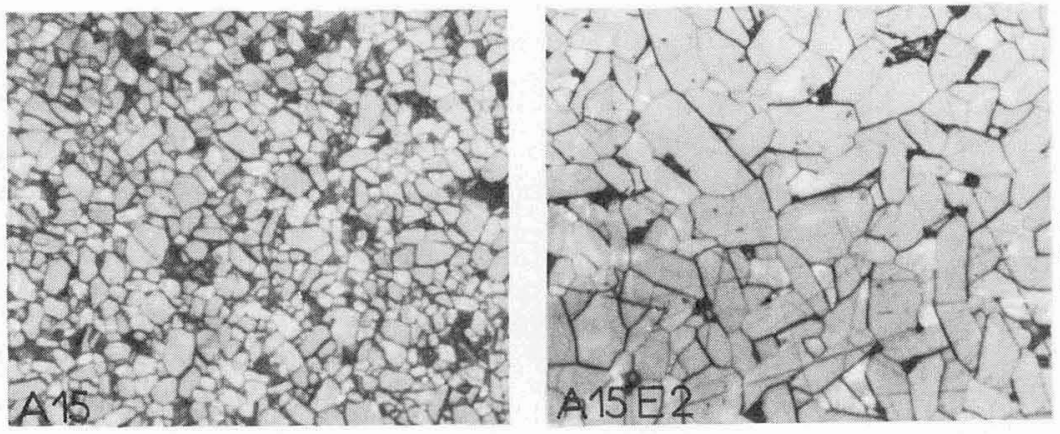

Fig. 1 - Micrographs of SiC-A15 and $\mathrm{SiC}-\mathrm{A} 15 \mathrm{E} 2$. 
These structures are typical examples of a mosaic structure. Regarding the morphological characteristics of such materials we have to investigate the mean grain size characteristics and their shape. As these materials are obtained by hot-pressing technic, a certain anisotropy in the crystals can arise. Finally we have also to approach the homogeneity of these materials by using the statistical methods.

This work has been performed with a texture analyzer system, TAS, from Leitz, which uses an hexagonal grid. Its design is based on mathematical morphology which allows to improve the images $/ 5 /$.

Measurements have been carried out on micrographs. After detection and memorization it was necessary to thin the grain boundaries as they shift the results when they reach a certain thickness. To obtain the minimum thickness, of one pixel, skeletonization by influence zone of the crystals has been utilized /6/. This skeleton was obtained by using the $\mathrm{L}_{6}$ neighbourhood configuration followed by a clipping by the $E_{6}$ neighbourhood configuration. Then the image is ready for measurement (Fig. 2).
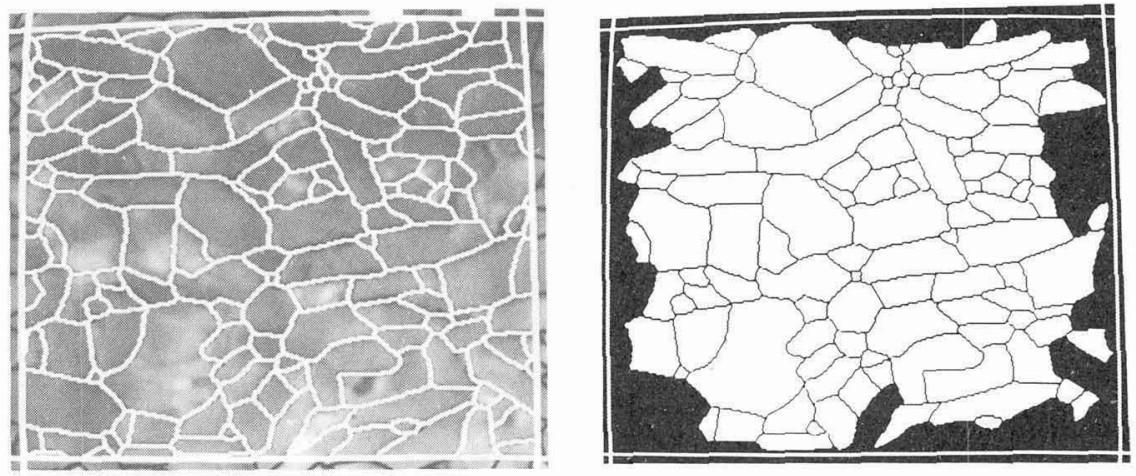

Fig. 2 - Skeletonized image superposed to its optical micrograph and detected image with the crystals totally included in the frame of measurement.

\section{III - GRAIN SIZE CHARACTERISTICS}

Among the different possible grain size methods, we have chosen the analysis particle by particle as these structures do not present interconnected phases and as the crystals are sensitively convex. The crystal surface area, $A_{i}$, totally included in the frame of measurements has been measured. To take into account that each grain does not possess the same probability to be included in this frame of measurements, a corrective method on the numbering, called frame measurement correction /7/, has been used : to each particle totally included in the frame of measurement, one assigns a statistical weight, equal to the ratio of the surface area of the frame of measurements over the surface area of this same frame, but eroded by the minimal rectangle circumscribed to the particle.

On figure 3 are presented the results in the mean grain size density form. From these curves, the interquantile deviation between the values of the measured surface areas for a frequency of 25,50 and $75 \%$, has been calculated for each batch of Sic. In order to compare these distributions to a normal logarithmic law, Henry tests have also been plotted (Fig. 4). These different results are listed on Table I.

From this table one notes that :

- the mean grain sizes of the SiC crystals for SiC-AO3 and Al5 are sensitively of the same order of magnitude,

- after thermal treatment of the SiC-A15 batch, the crystal growth of SiC-Al5 E2 batch is very important. This growth does not modify sensitively the grain size distribution,

- the analysis of the reduced interquantile deviation shows that a stability in the grain size dispersion exists. The same result is indicated, with less accuracy, by the values of the standard deviation. This last one is, in fact, very affected by the extremities of the distribution which are depending on much more important errors,

- regarding the shape of the distribution curves, gausso-logarithmic scale has been 

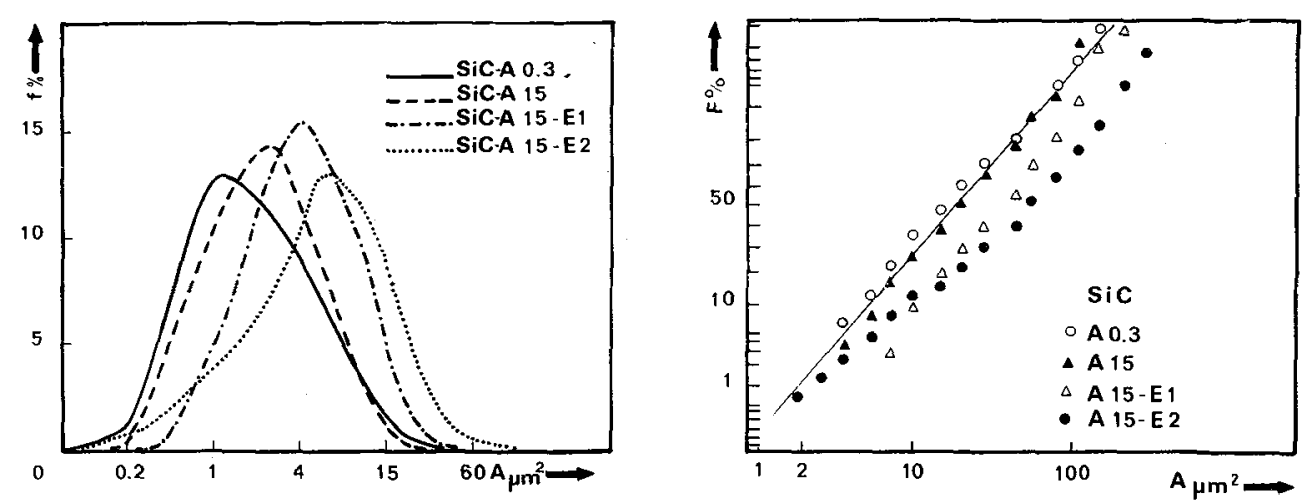

Fig. 3 - Mean grain size density dis- Fig. 4 - Henry test for the four batches. tribution for the four batches of $\mathrm{SiC}$.

used to plot the cumulated frequencies. One notes that the grain size distributions of materials without growth follow a logarithmic-normal law. On the other hand, those for materials with growth (El and E2) deviate notably from this law. This is probably due to the phenomena of accomodation of grains and of the anisotropy of crystalline growth.

\begin{tabular}{|c|c|c|c|c|}
\hline Characteristics & $\mathrm{SiC} A 03$ & SiC Al5 & SiC Al5 El & SiC Al5-E2 \\
\hline Mean area $A\left(\mu m^{2}\right)$ & 3.0 & 3.2 & 5.5 & 9.3 \\
\hline Standard deviation $\sigma\left(\mu \mathrm{m}^{2}\right)$ & 3.6 & 3.0 & 4.6 & 10.3 \\
\hline Reduced standard deviation $\sigma / \bar{A}$ & 1.20 & 0.94 & 0.84 & 1.11 \\
\hline A $1 / 4\left(\mu m_{2}^{2}\right)$ & 0.8 & 1.0 & 1.9 & 2.2 \\
\hline A $1 / 2\left(\mu \mathrm{m}_{2}^{2}\right)$ & 1.5 & 2.0 & 3.0 & 4.9 \\
\hline A $3 / 4\left(\mu \mathrm{m}^{2}\right)$ & 3.3 & 4.0 & 6.2 & 10.3 \\
\hline A $1 / 2-$ A $1 / 4\left(\mu m_{7}^{2}\right)$ & 0.7 & 1.0 & 1.1 & 2.7 \\
\hline A $3 / 4-$ A $1 / 4\left(\mu m_{?}^{2}\right)$ & 2.5 & 3.0 & 4.3 & 8.0 \\
\hline A 3/4-A $1 / 2\left(\mu m^{2}\right)$ & 1.8 & 2.0 & 3.2 & 5.4 \\
\hline $\begin{array}{l}\text { Reduced interquantile deviation } \\
\text { (A 3/4-A } 1 / 4 \text { )/ }\end{array}$ & 0.83 & 0.94 & 0.78 & 0.86 \\
\hline
\end{tabular}

TABLE I

Grain size characteristics of the SiC batches.

IV - SHAPE

As the crystals are not always equiaxed, we have characterized their shape by using several shape indexes. Among the numerous possible parameters, we have chosen three

shape indexes $/ 4 /$ : mean surface area and the mean perimeter of the crystals,

- F2, which represents the deviation from the convexity. It is measured by the ratio of the convex hull perimeter over the object perimeter,

- F3, which characterizes more specially the anisotropy : each grain is modelized by an ellipse, the eccentricity of which is obtained from the measurement of the projections in the three directions of the hexagonal grid.

Results are given in Table II. From these, one notes that :

- Fl does not appreciably evolve,

- the deviation from the convexity is extremely small: the crystals remain there- 


\begin{tabular}{|l|c|c|c|c|}
\hline & SiC AO3 & SiC A15 & SiC A15-E1 & SiC A15-E2 \\
\hline F1 & 0.68 & 0.69 & 0.71 & 0.68 \\
F2 & 0.98 & 0.99 & 0.99 & 0.99 \\
F3 & 0.72 & 0.72 & 0.73 & 0.79 \\
\hline
\end{tabular}

Table II

Values of the shape indexes used.

fore always convex whatever the batch is,

- the values of parameters F3, deviation from the eccentricity, are approximately of the same order of magnitude for $\mathrm{SiC}-\mathrm{A03}, \mathrm{A} 15$ and $\mathrm{Al5}-\mathrm{El}$ materials. These values point out that the crystals are perceptibly elongated. For SiC-Al5 E2 the value of this shape index is much higher. This indicates that this material has suffered a non-equiaxial growth. The fact that the crystals are individually anisotropic does not mean that the material is globally anisotropic. This necessitates a more important investigation of this characteristic.

\section{$\mathrm{V}$ - ANISOTROPY}

To characterize the anisotropy of relatively convex grains, either the intercept rose $/ 8 /$ or the direction rose $/ 4,5 /$ can be plotted. As the rose of direction is more sensitive to the anisotropy, we have chosen this last method.

By definition, the rose of directions is the length of the grain boundaries oriented in a given direction, divided by the surface area of the frame of measurements (Fig. 5). With the hexagonal grid, these lengths have been measured according to 6 orientations : $0, \pi / 3,2 \pi / 3, \pi / 6, \pi / 2$ and $5 \pi / 6$, using a neighbourhood transformation belonging to each direction.

Fig. 6 - Roses of directions for SiC-AI5 and A15-E2.

Fig. 5 - Schematic of the measurements with the rose of directions.
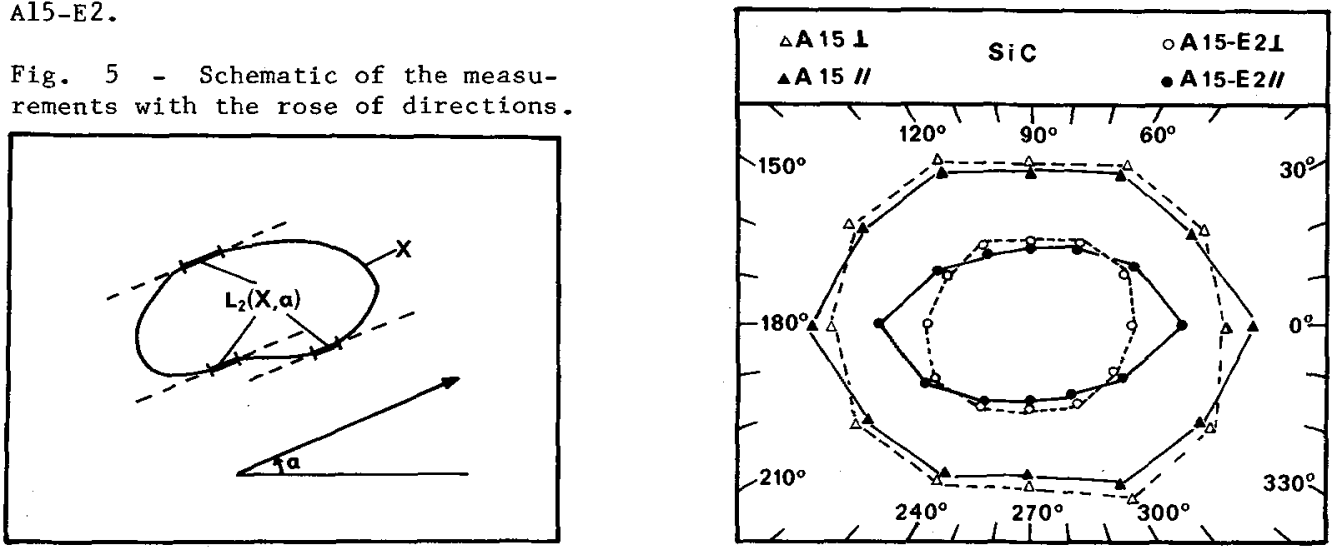

Results are reported on figure 6. One notes that the metallographic sections, for which the main direction is parallel to the compression axis, show an anisotropy more appreciable than that observed for the perpendicular direction. This anisotropy can also be modelized with an ellipse for which the axis have been calculated graphically (Table III). The eccentricity, e, can then be calculated from the relation:

$$
e=\sqrt{1-\left(\frac{a}{b}\right)^{2}}
$$

where $a$ and $b$ are the values of the half-axis of the ellipse.

In all cases, a small effect of the anisotropy is observed in the analysis direction parallel to the compression direction. This anisotropy effect is especially important since the material has been subjected to a large thermal treatment. 


\begin{tabular}{|c|c|c|c|c|}
\hline \multirow{2}{*}{$\begin{array}{c}\text { analysis } \\
\text { direction }\end{array}$} & \multicolumn{2}{|c|}{ SiC A15 } & \multicolumn{2}{|c|}{ SiC A15-E2 } \\
\cline { 2 - 5 } & $\perp$ & $/ /$ & $\perp$ & $/ /$ \\
\hline a/b & 0.84 & 0.69 & 0.76 & 0.53 \\
$\mathrm{e}$ & 0.54 & 0.72 & 0.64 & 0.85 \\
\hline
\end{tabular}

TABLE III

Values of eccentricity for the batches SiC Al5 and Al5-E2.

\section{VI - MORPHOLOGICAL HOMOGENEITY}

Using sintering processes, materials are generally very homogeneous compared to materials obtained by usual metallurgy. So in a first attempt, a classical analysis

can be sufficient to precise this homogeneity.
On each analysis frame, we haye measured the connexity number in $\mathrm{R}^{1}$ (number of grains per unit length) and in $\mathrm{R}^{2}$ (number of grains per unit surface) in order to test the homogeneity of these materials. The implied model assumes that the microstructure is uniform and that the setting of the frame is such that each variable is independant from one frame of measurement to the other. A regular setting was chosen in taking a net large enough with regard to the structure investigated. On Iable IV are given the results of $\mathrm{SiC}-\mathrm{A} 15 \mathrm{E} 2$ in two perpendicular directions. The Student test on this sampling shows that these materials present a very large homogeneity : in the most unfavourable case, we have a 93 to $96 \%$ probability to. find the mean value in an interval of $2.5 \%$ for $\mathrm{N}_{\mathrm{L}}$ and 97 to $98 \%$ in an interval of $5 \%$ for $\mathrm{N}_{\mathrm{A}}$.

\begin{tabular}{|l|c|c|c|c|c|c|c|c|}
\hline & $\mathrm{N}_{\mathrm{L}}$ & $\sigma\left(\mathrm{N}_{\mathrm{L}}\right)$ & ${\Delta \mathrm{N}_{\mathrm{L}}(2,5 \%)}_{\mathrm{P}}$ & $\overline{\mathrm{N}}_{\mathrm{A}}$ & $\sigma\left(\mathrm{N}_{\mathrm{A}}\right)$ & $\Delta_{\mathrm{A}}(5 \%)$ & $P$ \\
\hline direction 1 & 838 & 40.72 & 20.95 & 0.96 & 128307 & 10503 & 6415.35 & 0.98 \\
direction 2 & 675 & 38.37 & 16.87 & 0.93 & 126216 & 11867 & 6310.80 & 0.97 \\
\hline
\end{tabular}

TABLE IV

Results concerning the sampling of the batch SiC Al5-E2.

Results relative to $\mathrm{N}_{\mathrm{A}}$ are a somewhat less good. This is normal because $\mathrm{N}_{\mathrm{A}}$ is obtained from the second ${ }^{A}$ derivative while $\mathrm{N}_{L}$ is obtained from the derivative.

VII - CONCLUSION

Such materials are now well characterized from the morphological point of view. It is then possible to have experimental microstructural values which can be used to explain deviations from well defined phenomenological relationships.

\section{REFERENCES}

/1/ Moussa, R., Thèse de Doctorat ès-Sciences, ISMRa-Université de Caen (1985).

/2/ Moussa, R., Chermant, J.L. and Osterstock, F., IInd Int. Conf. on "Creep and Fracture of Engineering Materials and Structures", Swansea, U.K., 1-6 April 1984, Edited by Wilshire, B. and Owen, D.R.J., Pineridge Press (1984) 541.

13/ Chermant, J.L., Osterstock, F., Mat. Sci. Eng., 71 (1985) 147-157.

14/ Coster, M., Chermant, J.L., "Précis d'analyse d'images",Editions du CNRS (1985).

/5/ Serra, J., "Image analysis and mathematical morphology", Academic Press (1982).

16/ Lantuejoul, C., Skeletonizations. Rapport interne du Centre de Géostatistique et de Morphologie Mathématique, Ecole des Mines, Fontainebleau (1979) $\mathrm{n}^{\circ} 593$.

17/ Lantuejou1, C., Pract. Met., S8 (1978) 40.

18/ Underwood, E.E., Quantitative Stereology, Addison Wesley (1970). 